\title{
CORRESPONDENCE
}

\section{vTrs compunis}

To the editor:

Tam writing to correct some inaccu1 racies in the otherwise excellent story entitled "Bringing Biotech to Animal Health Care," by Jennifer Van Brunt (July 1987, p. 679).

Saul Kit, professor of Baylor College of Medicine and scientific advisor to NovaGene (Houston, TX), is actually a coinventor of the OmnivacPRV pseudorabies vaccine (along with Malon Kit, founder of NovaGene and adjunct research assistant professor at Baylor College of Medicine). Saul Kit has no financial interest in NovaGene.

Also, the article neglects to mention that in March of 1986 Baylor College of Medicine and NovaGene announced a second-generation genetically engineered pseudorabies vaccine with a test to serologically distinguish vaccinated from pseudorabiesinfected animals. Finally, the table on "Vaccines and Their Developers" fails to list the thymidine kinase-negative bovine infectious rhinotracheitis vaccines invented by Saul and Malon Kit.

Saul Kit, Ph.D. Head, Division of Biochemical Virol-

Baylor College of Medicine Texas Medical Center Houston, TX 77030

\section{BOFHRINGER MAMHHEM'S CBEANRATON}

To the editor:

A rthur Klausner's article, "ImmuAnoassays Flourish in New Markets" (June '87), was interesting and informative, and it showed that plant disease diagnosis is indeed a growing area with plenty of opportunity for the future.

I would, however, like to correct some of the information presented about our company and its products. Our company is Boehringer Mannheim Biochemicals, a division of Boehringer Mannheim Corporation $(\mathrm{BMC}) . \mathrm{BMC}$ is a U.S. (not a West German) company, but we do have strong ties with Boehringer Mannheim $\mathrm{GmbH}$ in West Germany, a sister company. Boehringer Mannheim Diagnostics (mentioned in the article) is another division of $\mathrm{BMC}$ here in the U.S., but they do not make phytodiagnostic reagents.

Boehringer Mannheim Biochemi- cals is a well-known supplier of products for molecular biology, immunology, analytical biochemistry, and cell culture. Our plant diagnostic products are part of what we call our "Food Technology" area, for which we are less well-known. Besides our ELISA-based test kits for detecting potato viruses, we offer individual reagents for the detection of other plant viruses, such as apple mosaic, plum pox, tomato ringspot, prunus necrotic, and beet necrotic yellow vein. We also offer reagents for the detection of ornamental plant viruses, including carnation mottle, Cymbidium mosaic, and Odonloglossum ringspot, as well as an RNA/DNA hybridization EIA kit for detection of potato spindle tuber viroid (PSTV).

Kristen E. Kinkade Product Manager

Boehringer Mannheim Biochemicals Indianapolis, IN 46250

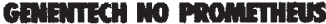

To the editor:

T found great irony in comparing August's "First Word" editorial with Amanda Iles' "Last Word." In the former, you hint at the hubris behind some of the travails of Genentech et al. yet persist in the notion of the "great" being punished. You proceed in a welter of self-pity to bemoan that "you do your best.....and you get pilloried for it."

Let us remember that most of us do science either because it interests us, or because (at last) there is a chance to make some money doing it. The fact that we may benefit humankind is a pleasant happenstance, but let's not be fooled into seeing ourselves as martyrs. Your remarks merely add self-righteousness to the hubris. Genentech a Prometheus? Let's get serious.

I find Jeremy Rifkin as irritating as you do. However, he would not have an audience or any supporters if it had not been for decades of arrogance and condescension toward the public on the part of practicing scientists. This is where you might have taken a cue from Ms. Iles. Her point about the importance of public understanding is well taken (even though it is presented with a trace of condescension). It has great applicability to the Genentech tissue-type plasminogen activator debacle: The deficiencies in the firm's application reflected not only inexperience and sloppiness, but contempt for and arrogance toward those with whom communication was essential.

I hope that as a spokesman for our industry, you will consider more closely the effects of our attitudes on the reception we receive from those whose response we depend upon.

Charles Hsu, Ph.D. Senior Scientist Invitron Corp. 515 Galveston Dr. Redwood City, CA 94063

\section{DEFINIne Blotechinolocr}

To the editor:

D ravo for your excellent and per1 suasive editorial entitled "Revival Meeting" (Bio/Technology 5:415 May '87). I have long "preached" to my students that the risk-benefit ratio with respect to biotechnology was enormously in favor of benefit.

Professor William H. Stone

Cowles Distinguished Professor of Biology

Trinity University 715 Stadium Drive San Antonio, TX 78284

P.S. To make a distinction, I define (for my students) the following: Genetic Engineering: the basic science of manipulating genes and organisms to construct novel biological entities; Biotechnology: the techniques that use living organisms, or parts of organisms such as cells, to make or to modify products, to improve plants or animals, or to develop microorganisms for specific applications.

\section{Eonanu}

The editors regret that "Rapid Production of Transgenic Flowering Shoots and F1 Progeny from Nicotiana plumbaginifolia Epidermal Peels" by Toan Hanh Trinh, Seth Mante, Eng-Chong Pua, and Nam-Hai Chua (Biol Technology 5:1081-1084, Oct. '87) appeared with its first figure inverted-a circumstance that may have hampered interpretation of the photo (on page 1082) of a transgenic shoot of $N$. plumbaginifolia with three flowering buds. 